\title{
Factores críticos de la planificación del desarrollo territorial en El Salvador
}

El Salvador ha acumulado, en los primeros quince años del siglo XXI, una valiosa experiencia en materia de planificación del desarrollo territorial. A nuestro criterio, una de las características más sobresalientes de esta etapa - a diferencia de ejercicios anteriores previos a la guerra civil- es la aspiración a lograr crecientes niveles de participación ciudadana, "de abajo hacia arriba", en planes de escala municipal y subregional en asociaciones de municipios. Esto representa, hacia el final de 2015, una oportunidad histórica para consolidar la práctica de la planificación en diferentes escalas del quehacer nacional, a la vez que plantea numerosos desafíos para asumir a plenitud la potencialidad de esta función pública.

Basta hacer un breve recorrido en el tiempo para confirmar esta aseveración. En este lapso, el Gobierno nacional, a través del Viceministerio de Vivienda y Desarrollo Urbano (VMVDU) y del Ministerio del Medio Ambiente y Recursos Naturales (MARN), formuló el Plan Nacional de Ordenamiento y Desarrollo Territorial (PNODT, 2004), el primero de su escala en la región centroamericana. Entre 2005 y 2011, fueron elaborados catorce planes regionales de Ordenamiento y Desarrollo Territorial que cubren la totalidad del territorio nacional. Como parte de ese mismo proceso, se han montado al menos cinco Oficinas de Planificación y Gestión Territorial (OPLAGEST) que, sumadas a la Oficina de Planificación del Área Metropolitana de San Salvador (OPAMSS), cubren más de sesenta municipios que han adquirido competencias plenas para el otorgamiento de permisos de construcción y calificación del suelo.

Adicionalmente, en los últimos cinco años, el Proyecto de Fortalecimiento de los Gobiernos Locales (PFGL), la Subsecretaría de Desarrollo Territorial y Descentralización (SSDT), con el apoyo del Fondo de Inversión Social para el Desarrollo Local (FISDL), han promovido la elaboración de 94 Planes Estratégicos Participativos (PEP) con énfasis en el desarrollo económico local. En cada municipio, se crearon espacios permanentes de participación ciudadana que se comentan con detalle en el cuarto artículo de este número. Una característica novedosa de este proceso fue su institucionalización a través de la aplicación de pautas metodológicas que orientaron su elaboración y construcción participativa

No menos significativo es el esfuerzo impulsado desde la Agencia de los Estados Unidos para el Desarrollo Internacional (USAID) en la formulación de planes municipales de competitividad junto a estrategias de desarrollo económico local encaminadas a fortalecer los tejidos económicos y la gene- 
ración de un entorno propicio para su desarrollo a nivel municipal. En estas experiencias, también se ha incluido la organización de comités de competitividad como instancias de articulación entre el sector empresarial y las municipalidades, algo poco común en otras experiencias.

Finalmente, cualquier observador podrá detectar en el territorio una amplia diversidad de planes más específicos, que se superponen entre sí: gestión de riesgos, turismo o desarrollo en general.

En medio de ese rico contexto, la Universidad Centroamericana José Simeón Cañas (UCA) ha participado, a través de los equipos de la Maestría en Desarrollo Territorial (MDT) y del Departamento de Organización del Espacio (DOE), en dos grandes estudios para conocer con detalle los avances y retos pendientes de estos procesos de planificación. Entre 2012 y 2013, la MDT-DOE elaboró el proyecto de investigación denominado "Construcción $e$ implementación de planes de ordenamiento y desarrollo territorial en El Salvador: las capacidades de los actores en el AMSS

Estos actores territoriales se han agrupado en espacios colectivos, consejos ciudadanos, comités, grupos gestores, para impulsar los procesos de planificación, formular planes y tomar decisiones. y la región Los Nonualcos 2000-2012"; y en 2014, realizaron la "Gestión del conocimiento del proceso de planificación estratégica participativa". Esto nos ha permitido analizar un amplio caudal de hechos empíricos y experiencias reales para construir un relato sobre la planificación en El Salvador, asumiendo una perspectiva académica crítica, con importantes implicaciones para la formulación de políticas y la potenciación de experiencias.

Nuestro enfoque ha puesto énfasis en el concepto de "capacidades", tempranamente definido por Ellacuría (1999) como un saber estar, saber ser y saber actuar de naturaleza colectiva que permite a los grupos sociales apropiarse de las posibilidades históricas. Las mismas capacidades fueron elaboradas por Nussbaum (2011), que las define como posibilidades funcionales de actuación en la sociedad. Particularmente, en el caso de la planificación proponemos una clasificación de capacidades de agencia de actores organizacionales en dos categorías: las políticas, relativas a la operación de redes de actores y a la definición de visiones conjuntas; y las técnicas, relacionadas con la gestión e incorporación de conocimiento y con el manejo del proceso mismo.

\section{Desde esa mirada, ¿cuáles son las lecciones aprendidas que dejan estos recientes procesos de planificación de ordenamiento y desa- rrollo territorial en El Salvador?}

Nos parece que, en los últimos quince años, en el país se ha producido una importante acumulación de capacidades de planificación del desarrollo territorial. Nos referimos a capacidades políticas de los actores territoriales que se reflejan en el rol cada vez más protagónico, podríamos decir indispensable, que han asumido los gobiernos municipales con sus equipos técnicos. En muchas de las experiencias que se comentan en los primeros cuatro 
artículos de este número, se evidencia que municipalidades individuales, como las de Santa Tecla o Tecoluca, o asociaciones municipales, como el COAMSS o la Asociación Los Nonualcos (ALN), han liderado esfuerzos significativos de planificación muchas veces sin necesidad de contar con el soporte del Gobierno nacional. Usualmente, participan movimientos sociales organizados, organizaciones no gubernamentales de escala local y nacional, y asociaciones de productores; en muchos casos, han contado con apoyo
En síntesis, está pendiente lograr una articulación efectiva de los actores extraterritoriales, gubernamentales y empresariales, en la planificación local y entre localidades, a través de la planificación microregional y regional. financiero de organismos multilaterales de cooperación y facilitación técnica de actores exógenos. De esa manera, sin aspirar a contar con la unanimidad de los actores del territorio, se han construido coaliciones más o menos amplias y diversas, capaces de llevar adelante los procesos y asumir su continuidad después de formularlos. Estos actores territoriales se han agrupado en espacios colectivos, consejos ciudadanos, comités, grupos gestores, para impulsar los procesos de planificación, formular planes y tomar decisiones.

Igualmente valioso es el hecho de que estos actores han sido capaces de crear y operar nuevas reglas del juego para el territorio y, en definitiva, han alterado las relaciones de poder presentes. Esto por medio de la aprobación formal de los planes, la elaboración y puesta en práctica de ordenanzas, reglamentos y, muy importante, la movilización de recursos propios o externos para concretizar las propuestas de proyectos e intervenciones en el territorio.

También destacamos las capacidades técnicas para la formulación de planes. Más allá de la participación activa de los gobiernos locales, también sobresale la presencia de equipos de expertos nacionales e internacionales con conocimientos especializados en temas críticos para la realidad territorial. Estos equipos amplios han sabido actuar de forma coordinada y han asumido en general una perspectiva holística integradora de las diversas dimensiones del territorio. Particularmente, se le ha puesto atención a la formulación e implementación de bancos de proyectos detonadores localizados en el territorio, de naturalezas muy diversas. Más importante todavía, muchos de esos proyectos se han ejecutado con inversión municipal. En algunos casos se ha delegado la gestión a las mismas comunidades. Menos consolidada, pero igualmente relevante, es la formulación de diversas estrategias e instrumentos para la generación de recursos económicos a través de figuras asociativas o instrumentos fiscales.

No obstante, incluso en las historias más exitosas, hemos detectado múltiples debilidades que deben indicar caminos de acción a futuro para fortalecer capacidades endógenas de planificación. En cuanto a las capacidades políticas, aún queda pendiente la articulación efectiva de actores territoriales de escala nacional, particularmente del Gobierno nacional, con los de escala local. Menos resuelta aún está la organización de la escala intermedia de naturaleza asociativa, regional o departamental. También es notable la ausencia, en la mayoría de procesos, de los actores empresariales territoriales y extraterritoriales, especialmente las medianas y grandes empresas. En gene- 
ral, podemos decir que los procesos de planificación del desarrollo territorial desde la escala local tienden al localismo y pierden la perspectiva respecto de las relaciones con otros territorios y el ámbito nacional. En síntesis, está pendiente lograr una articulación efectiva de los actores extraterritoriales, gubernamentales y empresariales, en la planificación local y entre localidades, a través de la planificación microregional y regional.

Lo anterior, se refleja, a nivel de capacidades técnicas, en la dificultad para abordar los procesos macro de cambio territorial en los que los actores foráneos tienden a desempeñar un papel dominante. De ahí que, aunque los planes comiencen a implementarse, dejan la sensación de no estar alterando las dinámicas más estructurales, ya sea de actividad económica, exclusión social o la calidad de vida. También sobresale la ausencia de procesos sistemáticos de seguimiento, monitoreo y evaluación de las experiencias de planificación, lo que dificulta la consolidación de prácticas a través del aprendizaje crítico y constructivo de la experiencia.

¿Por qué existen experiencias más o menos exitosas de planificación del desarrollo territorial a escala local y de asociaciones de municipios?

Nos interesa dilucidar los elementos que condicionan los procesos de planificación y que a la larga determinan el despliegue de las capacidades y la obtención de los resultados deseados. Proponemos tres, de naturaleza esencialmente endógena, arraigados en las condiciones del territorio y que, por lo tanto, deberían ser considerados a la hora de promover políticas desde el ámbito nacional.

Un primer elemento esencial es la continuidad de los equipos técnicos y políticos vinculados con la planificación del desarrollo territorial, acompañados de un mínimo de recursos humanos y materiales a lo largo del proceso. Esto subraya la importancia de entender la planificación como proceso, cíclico o iterativo, pero de carácter permanente. Además, nos recuerda que la construcción de capacidades de planificación endógenas territoriales requiere tiempo, tanto para acumular e integrar nuevos conocimientos, como para consolidar una práctica propia de formulación, implementación y evaluación.

Un segundo aspecto crítico es la presencia de un liderazgo político en el territorio, usualmente a nivel de la administración municipal. Dicho liderazgo debe apostarle a la planificación como instrumento estratégico para promover el cambio territorial y, en definitiva, "la transformación de las relaciones de poder" en el territorio. Esto a la vez, significa que la planificación del desarrollo territorial debe admitir y potenciar su plena dimensión política y comunicacional.

Un tercer factor fundamental que explica la buena marcha de los procesos de desarrollo territorial a nivel local es la acumulación de experiencias previas de planificación participativa. Es decir, donde la planificación tiene 
mayores posibilidades de éxito y de asegurar su legitimidad social es en aquellos territorios en los cuales han existido prácticas más arraigadas de organización social, dinámicas de consulta, diálogo y negociación entre actores diversos. En otras palabras, la planificación tiene historia y, ahí donde los antecedentes sean más ricos y robustos, se pueden esperar mejores resultados de los procesos que den continuidad y profundicen estos ejercicios anteriores.

\section{A partir de ese marco, ¿qué hacer para potenciar los procesos par- ticipativos de planificación del desarrollo territorial en El Salva- dor?}

Nuestro propósito último al interesarnos por la planificación de escala territorial —subnacional - es insistir en la posibilidad de elaborar y poner en práctica políticas públicas que potencien las experiencias acumuladas y superen las debilidades detectadas. A la larga, se trata de identificar elementos sobre los que un eventual sistema nacional de planificación debería poder actuar y, con ello, asegurar mejores condiciones de práctica. Identificamos cinco grandes condicionantes.

Primero, nuestro trabajo empírico devela que, a pesar de los avances ya comentados, los concejos

Nos parece crítico asegurar la convocatoria y, más importante, la permanencia del universo amplio de intereses locales, más allá de diferencias ideológicas. municipales se involucran de formas muy diversas, más o menos proactivas, en los procesos de planificación, particularmente cuando estos vienen orientados desde el Gobierno nacional. Cuando la municipalidad asume el liderazgo, delega concejales para dar seguimiento, facilita la participación de técnicos, compromete recursos y respeta los espacios multiactores, se tienen las condiciones óptimas para procesos más efectivos. Cuando el gobierno local se involucra de forma marginal, satura a los técnicos en múltiples actividades, coopta los espacios de participación y es completamente dependiente de recursos exógenos; entonces, los procesos son frágiles y difícilmente llegan a arraigarse en el territorio y sostenerse en el tiempo.

Segundo, los procesos de participación para la planificación del desarrollo territorial necesitan de condiciones previas particulares, notablemente la preparación de los actores, el cuidado de su representatividad y el manejo de técnicas básicas de comunicación y negociación. Se trata de la construcción de verdaderos sujetos en el territorio. Como se ha dicho, en aquellos territorios donde esta construcción esté más avanzada, por diversos antecedentes, habrá mejores oportunidades para llevar adelante procesos exitosos. Evidentemente, esto no puede lograrse de la noche a la mañana. Por ello, insistimos en la importancia de la dimensión histórica de la planificación, la cual entendemos, entonces, como un proceso continuo de construcción de capacidades con una visión prospectiva de medio y largo plazo.

Tercero, a la par que se propician las mejores condiciones para emprender procesos participativos de planificación territorial a nivel local, es indis- 
Los procesos de formulación e implementación de planes de desarrollo territorial necesitan experticias particulares, conocimientos específicos, recursos para la inversión y articulación de intereses más allá de lo local. pensable superar algunas debilidades frecuentes de las dinámicas participativas. Es fundamental lograr una adecuada representatividad de los actores territoriales clave, tanto a nivel de movimientos sociales como empresariales. Nos parece crítico asegurar la convocatoria y, más importante, la permanencia del universo amplio de intereses locales, más allá de diferencias ideológicas. Reivindicando el carácter ético de la planificación, es necesario que esta contribuya a visibilizar los intereses de grupos vulnerables, muchas veces dispersos y sin mayor organización, como colectivos de mujeres, jóvenes, adultos mayores o personas con capacidades especiales.

Cuarto, como decíamos anteriormente, los procesos participativos de planificación del desarrollo territorial a nivel municipal y de asociaciones de municipios necesitan el involucramiento activo de actores extraterritoriales. Independientemente del nivel de liderazgo y proactividad de los actores territoriales, es indispensable integrar en dichas dinámicas al Gobierno nacional, las ONG especializadas en temas puntuales, universidades, grandes empresas y agencias de cooperación. Los procesos de formulación e implementación de planes de desarrollo territorial necesitan experticias particulares, conocimientos específicos, recursos para la inversión y articulación de intereses más allá de lo local.

Quinto, para impulsar de forma estratégica los procesos de planificación de las dinámicas sociales en los territorios subnacionales, es indispensable superar la lógica todavía excesivamente centralista y sectorial del Gobierno nacional y el todavía débil esfuerzo de territorializar y gestionar, de forma intersectorial y multinivel, las políticas públicas. Esto tiene una doble implicación: por un lado, el impulso continuo de los procesos de desconcentración y descentralización; y por otro, el fortalecimiento del todavía incipiente nivel intermedio tanto a nivel de las asociaciones municipales como de las gobernaciones departamentales asociadas en regiones con apuestas propias para el desarrollo.. A nuestro criterio, es indispensable que estos espacios, mancomunidades, departamentos y regiones, asuman funciones de planificación y, por lo tanto, adquieran nuevas capacidades.

\section{A partir de lo anterior, ¿qué recomendamos específicamente al na- ciente Sistema Nacional de Planificación?}

Nos parece que hay que concentrar la atención en cuatro temas puntuales.

En el orden más conceptual y de principios, una política nacional de desarrollo territorial debería preocuparse por crear un marco general coherente que, por un lado, defina una visión estratégica nacional capaz de orientar los procesos territoriales, pero, por otro, reconozca la diversidad de experiencias y prácticas. Esto significa alejarse de los marcos normativos centrados en la elaboración de recetas y modelos únicos, sin renunciar por ello a proponer 
pautas estratégicas y flexibles y conjuntos de instrumentos aplicables según cada situación. La planificación del desarrollo territorial debe adaptarse a cada territorio.

Segundo, es indispensable vincular planificación desde territorios subnacionales e inversión pública. Esto de cara a responder de forma más efectiva a las demandas de los actores territoriales, articuladas y sistematizadas en los procesos de planificación. Además, ello facilitaría impulsar y poner en marcha proyectos estratégicos que aprovechen las potencialidades del territorio y detonen los procesos de cambio deseados en función de la reducción de desequilibrios y el fortalecimiento de la competitividad territorial. En definitiva, se trata de organizar un Sistema Nacional de Planificación e Inversión Pública.

El tercer tema crítico es apostar desde el nivel nacional por el fortalecimiento de las experiencias existentes exitosas y mejor consolidadas, como pueden ser entre otras las de Los Nonualcos y del área metropolitana de San Salvador, como experiencias piloto en función del aprendizaje. Esto implica sistematizar y difundir las experiencias, aportar recursos para fortalecer equipos técnicos y, sobre todo, apuntalar los procesos en marcha, nunca obstaculizarlos, sustituirlos o desarticularlos.

Finalmente, reiteramos la importancia estratégica de construir o fortalecer las capacidades de gestión territorial de la escala intermedia entre lo nacional y lo local. Ello, ya sea a través de la figura de las mancomunidades de municipios o la de los departamentos con visión regional. Nos parece claro que este fortalecimiento solo podrá ser efectivo si combina la construcción de capacidades técnicas y políticas para la planificación del desarrollo territorial con la provisión de recursos que incentiven el desarrollo de proyectos estratégicos y estimulen estructuralmente los procesos de planificación participativa del desarrollo territorial. 